\title{
Comparison of GOME total ozone data with ground data from the Spanish Brewer spectroradiometers
}

\author{
M. Antón ${ }^{1, *}$, D. Loyola ${ }^{2}$, B. Navascúes ${ }^{1}$, and P. Valks ${ }^{2}$ \\ ${ }^{1}$ Área de Proyectos, Instituto Nacional de Meteorología (INM), C. Leonardo Prieto Castro, nº 8, CP: 28071, Madrid, Spain \\ ${ }^{2}$ Remote Sensing Technology Institute, German Aerospace Center (DLR), Oberpfaffenhofen, 82234 Wessling, Germany \\ *now at: Departamento de Física, Universidad de Extremadura, Avd. de Elvas, s/n, CP: 06071, Badajoz, Spain
}

Received: 13 March 2007 - Revised: 10 October 2007 - Accepted: 20 December 2007 - Published: 26 March 2008

\begin{abstract}
This paper compares total ozone measurements from five Brewer spectroradiometers located at the Iberian Peninsula with satellite observations given by the GOME (Global Ozone Monitoring Experiment) sensor. The analyzed period covers simultaneous ozone values from July 1995 until December 2004. The regression analysis shows an excellent agreement between Brewer-GOME values in the five locations; the coefficient of correlation is always higher than 0.92 and the root mean square error is about 3\%. Moreover, the comparison shows that the satellite retrieval accuracy is within the uncertainty of current ground-based instruments. In addition, the effects of several variables, such as cloudiness, solar zenith angle (SZA), effective temperature and total ozone values in Brewer-GOME differences are analyzed. The results indicate that clouds induce a minor dependence of GOME values on the SZA. For example, during heavy cloudy conditions in Madrid station, GOME observations overestimate ground-based Brewer data for low AMF (low SZA values) by $2 \%$ while for high AMF (high SZA values) the satellite underestimates ground-based ozone values by $1 \%$. Moreover, the dependence of Brewer-GOME differences with respect to SZA for cloud-free conditions may be due to the variability of effective temperature. This fact could indicate that the effective temperature estimated by GOME does not fully reflect the actual atmospheric temperature variability. Finally, GOME ozone observations slightly underestimate the highest values measured by the Brewer spectrophotometers and overestimates the lowest ground-based measurements.
\end{abstract}

Keywords. Atmospheric composition and structure (Middle atmosphere - composition and chemistry; Instruments and techniques)

Correspondence to: $\mathrm{M}$. Antón

(mananton@unex.es)

\section{Introduction}

Satellite monitoring of the Earth's atmosphere allows one to globally record spatial and temporal information on different physical parameters. This information is required for different applications, such as climate change, numerical weather prediction and pollution monitoring.

One particular area where satellite monitoring has proven to be useful is in analysing global atmospheric ozone. Accurate ozone observations from remote sensing instruments play an important role in ozone trend analysis in order to assess current and future changes in the atmosphere. To that effect, the ESA Global Ozone Monitoring Experiment (GOME) has been recording global measurements of total ozone from July 1995 (Burrows et al., 1999). Since deployment, GOME has proven suitable for the generation of longterm data sets of trace atmospheric constituents; a series to be extended with GOME-2, launched in October 2006, on board METOP-1.

GOME data is routinely retrieved with the current off-line GOME Data Processor (GDP) which has undergone several years of progressive improvement since its first release in 1995 (Loyola et al., 1997). In order to guaranty the quality of satellite products a highly iterative development process is absolutely necessary. This process involves several steps, such as calibration, radiative transfer modelling, validation, algorithm refinements and reprocessing. To assure the quality of remote sensing measurements, the inter-comparison of satellite products by reliable ground-based measurements is a critical activity (WMO, 1999). In this sense, a number of validation studies identified several discrepancies in the initial versions of GDP with ground-based measurements, that were later resolved. The relative differences pass from $2 \%-$ $5 \%$ at $\mathrm{SZA}<70$ and $10 \%$ at $\mathrm{SZA}>70^{\circ}$ for GDP2.7 (Lambert et al., 1999) to the "percent level" in the current version GDP4.0 (Balis et al., 2007).

Published by Copernicus Publications on behalf of the European Geosciences Union. 
Table 1. Pairs of Brewer-GOME data considered in the comparison by year and location.

\begin{tabular}{lllllll}
\hline & Madrid & Murcia & Coruña & Zaragoza & Arenosillo & $\begin{array}{l}\text { Iberian } \\
\text { Peninsula }\end{array}$ \\
\hline 1995 & 43 & 49 & - & - & - & 92 \\
1996 & 78 & 84 & - & - & - & 162 \\
1997 & 67 & 87 & - & - & - & 154 \\
1998 & 81 & 79 & - & - & 60 & 160 \\
1999 & 76 & 82 & 71 & - & 67 & 296 \\
2000 & 85 & 73 & 66 & 17 & 61 & 302 \\
2001 & 69 & 66 & 63 & 55 & 60 & 313 \\
2002 & 80 & 80 & 64 & 73 & 69 & 366 \\
2003 & 44 & 56 & 43 & 54 & 51 & 248 \\
2004 & - & 72 & 65 & 69 & 69 & 275 \\
Total & 608 & 637 & 370 & 268 & 437 & 2320 \\
\hline
\end{tabular}

The main objective of this paper is to compare the GDP version 4.0 (van Roozendael et al., 2006) with ground-based Brewer spectroradiometers in Spain. Although global scale and large validation studies have been performed (e.g. Balis et al., 2007), the present work can be considered as complimentary since the Iberian Peninsula (region of the relevant interest for Europe) has not been evaluated before in detail. Moreover, the time series of data analyzed (ten years) and size of the data set (Table 1) is larger than the ones used previously (e.g. Hansen et al., 1999; Lambert et al., 2002; Bramstedt et al., 2003), allowing one to assess any differences over a wide range of spatial and temporal scales. Another relevant aspect of the Brewer data set is that only Direct Sunlight (DS) measurements (the most accuracy Brewer ozone data) have been used.

For comparison studies associated with validation, one must deal with a variety of problems arising from the remote sensing nature of the ozone measurements to be validated and the geophysical nature of the observed ozone field. These include differences in spatial and temporal resolution, differences in measurements time, dependences on solar zenith angle and effective temperature, cloudiness effects, etc. In this paper, some of these problems are minimized with the usage of strict co-location criteria (distance less than $150 \mathrm{~km}$, and time difference less than $45 \mathrm{~min}$ ). Moreover, when a network of instruments is used the absolute calibration of each instrument must be high, in order to ensure that there are no unknown station-to-station biases. In this direction, the Spanish Brewer instruments present an excellent maintenance (Labajo et al., 2004).

The paper is structured as follows: Sect. 2 discusses the satellite and ground-based data used in this study. Section 3 describes the method of the comparison. In Sect. 4 results are analyzed in order to evaluate the differences between Brewer measurements and GOME estimations. Finally, Sect. 5 summarizes our conclusions.

\section{Data}

\subsection{Satellite observations}

GOME, the first European space-borne, UV-visible-nearinfrared spectrometer, was launched on board the Second European Sensing Satellite (ERS-2) in April 1995. The satellite follows a Sun-synchronous polar orbit with a period of about $100 \mathrm{~min}$. Global coverage at the Equator is achieved with GOME within three days. The ground path $(960 \mathrm{~km})$ is divided into three ground pixels of $320 \mathrm{~km}$ (across orbit) $x$ $40 \mathrm{~km}$ (along orbit). A detailed instrument description can be found in the GOME User's Manual (ESA, 1995). GOME takes 3584 spectral channels in the range 240 to $793 \mathrm{~nm}$ with a spectral resolution of 0.2 to $0.4 \mathrm{~nm}$. In this paper, the GDP4.0 has been applied in order to derive total ozone. This technique is based on a standard Differential Optical Absorption Spectroscopy (DOAS) retrieval where slant columns retrieved from a spectral fit are converted to vertical column density (VCD) using air mass factors (AMFs) calculated at a single wavelength. GDP4.0 uses an iterative DOAS/AMF computation scheme with on-the-fly calls to the radiative transfer model LIDORT. The AMF computation is based on an ozone profile climatology classified by total column that has been made for the TOMS V8 total ozone algorithm.

The GDP4.0 includes two new algorithms for the treatment of clouds (Loyola, 2007). The OCRA algorithm uses data fusion techniques to derive the cloud fraction from the sub-pixel PMD measurements, while the ROCINN algorithm derives the cloud-top height and cloud-top albedo from the spectral fitting of reflectivity around the Oxygen A band. In the presence of clouds, the retrieved ozone column has to be corrected for the so-called "ghost vertical column" (GVC), which is the quantity of ozone below the cloud-top height that is not seen by GOME. The determination of GVC is based on cloud-top height information inferred from GOME measurements and the TOMSV8 ozone profile climatology. 
Table 2. Parameters obtained in the correlation analysis between satellite and ground-based measurements.

\begin{tabular}{lcccrc}
\hline & Slope & $R^{2}$ & RMSE (\%) & MBE (\%) & MABE (\%) \\
\hline Madrid & $1.01 \pm 0.01$ & 0.92 & 2.88 & $-0.93 \pm 0.12$ & $2.28 \pm 0.08$ \\
Murcia & $0.96 \pm 0.01$ & 0.93 & 2.65 & $-0.67 \pm 0.11$ & $2.14 \pm 0.07$ \\
Coruña & $0.98 \pm 0.01$ & 0.92 & 3.29 & $-1.16 \pm 0.13$ & $2.54 \pm 0.09$ \\
Zaragoza & $1.02 \pm 0.02$ & 0.92 & 2.36 & $-2.11 \pm 0.14$ & $3.29 \pm 0.10$ \\
Arenosillo & $1.01 \pm 0.01$ & 0.93 & 2.72 & $0.18 \pm 0.11$ & $2.09 \pm 0.07$ \\
Iberian Peninsula & $1.00 \pm 0.01$ & 0.92 & 3.04 & $-0.92 \pm 0.12$ & $2.28 \pm 0.08$ \\
\hline
\end{tabular}

Furthermore, the GDP4.0 includes a new molecular Ring correction to deal with inelastic rotational Raman scattering, and a spectral fitting of effective stratospheric temperature to account for the temperature dependence of the ozone cross sections in the ozone Huggins band.

\subsection{Ground-based measurements}

The Brewer spectrophotometer is a fully automated instrument which uses the principle of differential absorption. The total ozone amount is derived from the ratio of measured sunlight intensities at five wavelengths between 306 and $320 \mathrm{~nm}$ with a resolution of $0.6 \mathrm{~nm}$, where the absorption by ozone presents large spectral structures. The wavelengths used in the Brewer ozone measurements are chosen to avoid interferences by $\mathrm{SO}_{2}$. Moreover, interferences by $\mathrm{NO}_{2}$ may be neglected for Brewer measurements, except during strong $\mathrm{NO}_{2}$ tropospheric pollution events which can produce an erroneous increase in total ozone by $0.6 \%$ in extreme cases. Accurate Brewer total ozone amounts are obtained through direct sunlight (DS) measurements. The precision of the total ozone amount detected by the Brewer spectrophotometer through DS measurements may be estimated to $1.0 \%$ (WMO, 1996). A detailed description of the methodology used by the Brewer spectrophotometers to measure the total ozone amount from direct sunlight can be found in Kerr et al. (1984).

The Brewer data used in this paper are based on absorption coefficients at the fixed temperature of $-46.3^{\circ} \mathrm{C}$. It is known that these coefficients in the Huggins band are temperaturedependent. However, this temperature effect on Brewer data is not significant due to the wavelengths used (Kerr, 2002).

The Spanish National Institute of Meteorology (INM) operates a national Brewer spectrophotometer network. This network provides total ozone amount and spectral UV and it is monitored in real time through the intranet of INM. The ground-based stations used in this study are from north to south: Coruña $\left(43.33^{\circ} \mathrm{N}, 8.42^{\circ} \mathrm{W}\right)$, Zaragoza $\left(41.01^{\circ} \mathrm{N}\right.$, $\left.1.01^{\circ} \mathrm{W}\right)$, Madrid $\left(40.45^{\circ} \mathrm{N}, 3.72^{\circ} \mathrm{W}\right)$, Murcia $\left(38.03^{\circ} \mathrm{N}\right.$, $\left.1.17^{\circ} \mathrm{W}\right)$ and Arenosillo $\left(37.06^{\circ} \mathrm{N}, 6.44^{\circ} \mathrm{W}\right)$. All instruments are biannually calibrated by intercomparison with the traveling reference Brewer \#017 from the International

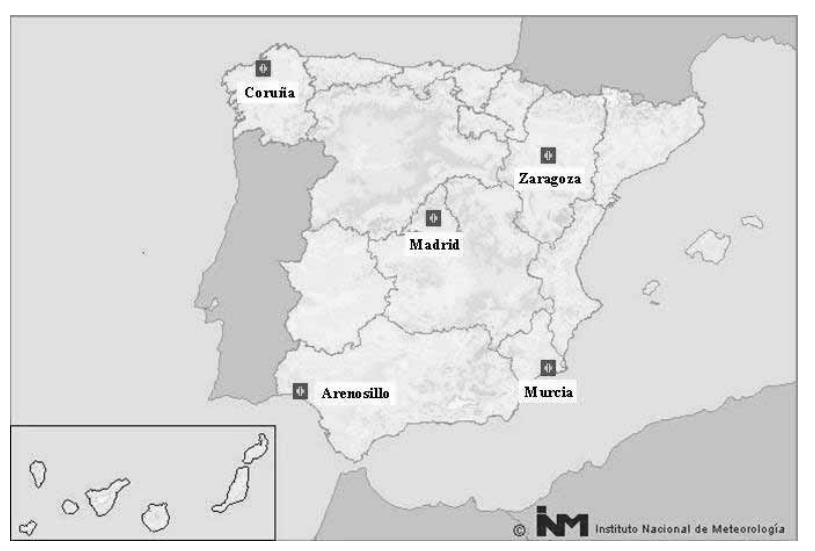

Fig. 1. Locations of the Spanish Brewer spectrophotomer network in the Iberian Peninsula.

Ozone Services (IOS). In this way the ozone calibration is traceable to the triad of reference Brewer spectrophotometers at the Meteorological Service of Canada. The four intercomparisons carried out at the El Arenosillo station with the reference traveling standard Brewer instrument confirm the reliability of Spanish Brewer calibration (Labajo et al., 2004). The locations of the Spanish Brewer spectrophotometers are shown in Fig. 1.

\section{Comparison procedure}

The study presented here uses GOME data within $150 \mathrm{~km}$ of the Brewer stations. The ground-based data selected for the comparisons are based on records of DS measurements. The Brewer measurement nearest to GOME overpass time (between 10.83 y 11.54 UTC hours) is selected everyday in order to gain the best time coincidence. The average time delay between the satellite observation and ground-based measurements ranges between $16 \mathrm{~min}$ at Arenosillo (minimum) and 44 min at Coruña (maximum).

Time series of both satellite and ground-based total ozone data extend from July 1995 to December 2004. Table 1 shows the number of quasi-simultaneous pairs of BrewerGOME data sorted by year and location. 
MADRID

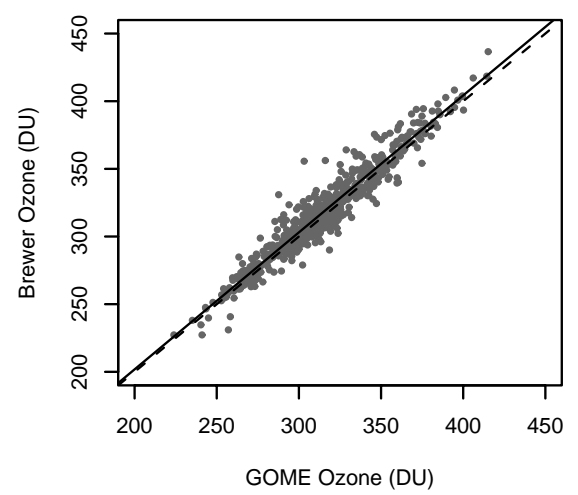

ZARAGOZA

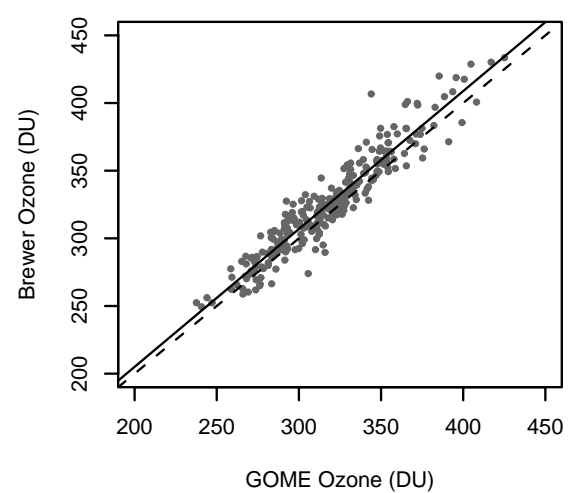

ARENOSILLO

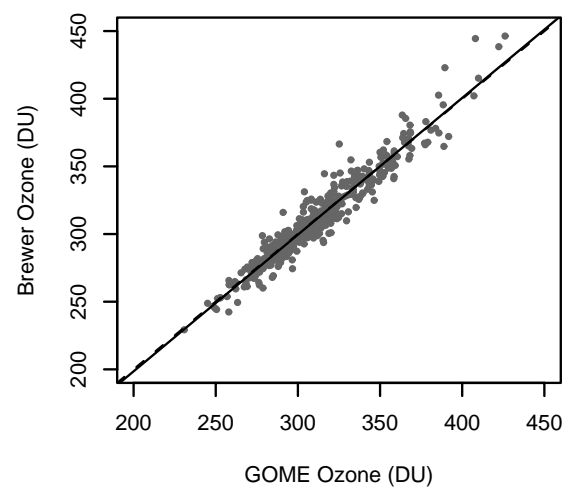

CORUÑA

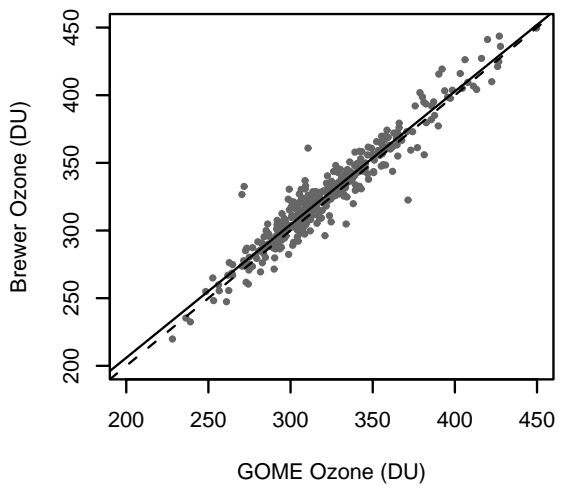

MURCIA

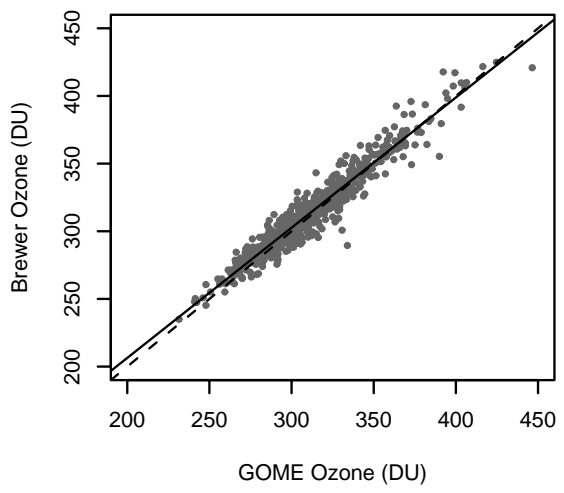

IBERIAN PENINSULA

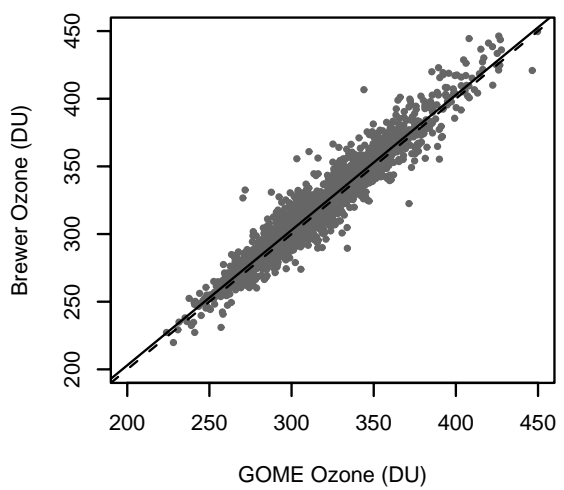

Fig. 2. Ozone amount measurements of Brewer spectrophotometer versus GOME satellite observations. Regression line (solid line) and unit slope (dashed line).

A regression analysis is performed for each location. Regression coefficients, coefficients of correlation (R2) and the root mean square errors (RMSE) were evaluated, and the mean absolute bias error (MABE) and the mean bias error (MBE) parameters were calculated for each station. These parameters are obtained by the following expressions:

$$
\mathrm{MABE}=\frac{100}{N} \sum_{i=1}^{N} \frac{\mid \mathrm{GOME}_{i}-\text { Brewer }_{i} \mid}{\text { Brewer }_{i}},
$$

$\mathrm{MBE}=\frac{100}{N} \sum_{i=1}^{N} \frac{\mathrm{GOME}_{i}-\text { Brewer }_{i}}{\text { Brewer }_{i}}$ 

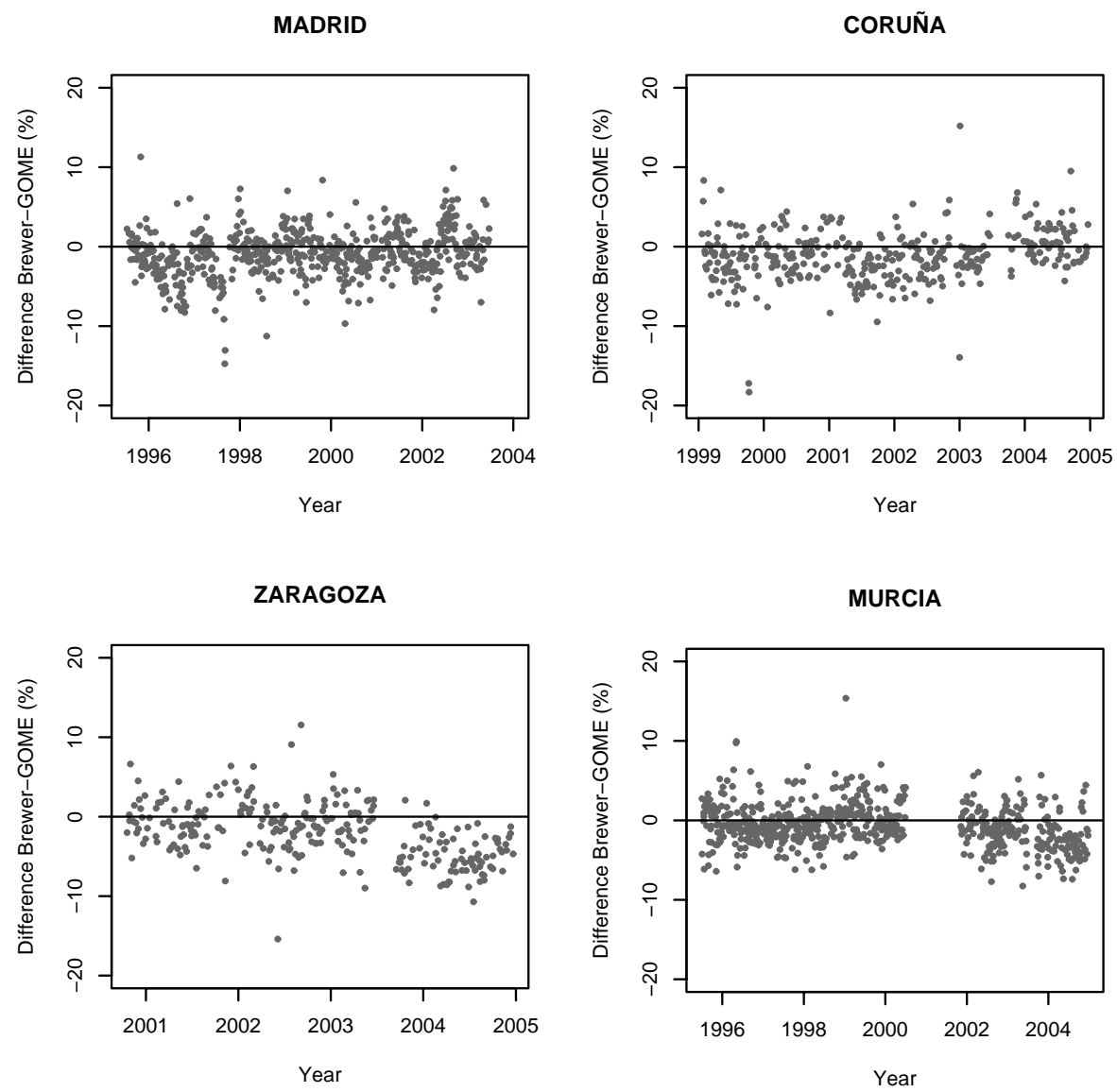

ARENOSILLO
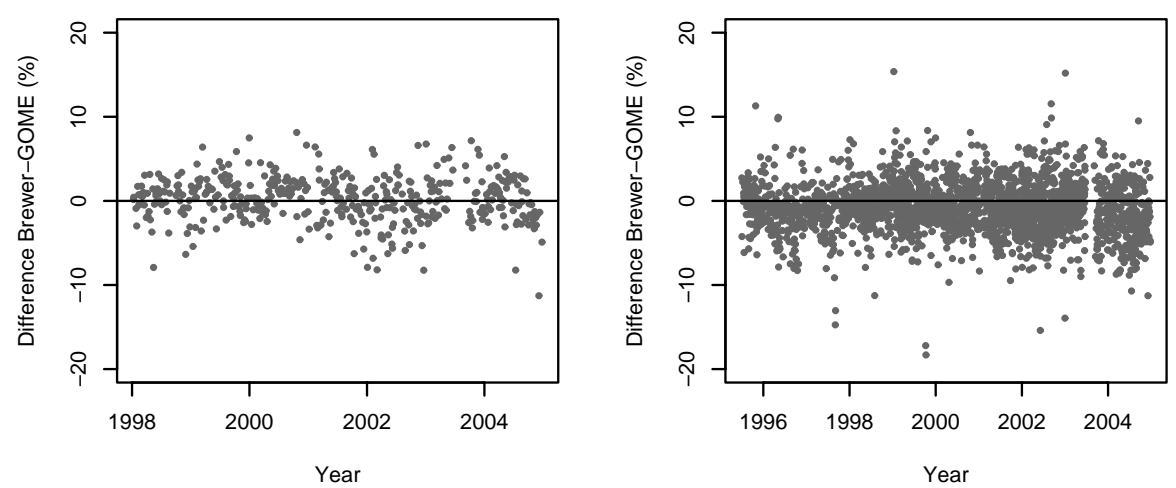

Fig. 3. Temporal evolution of the relative difference between TOMS and Brewer ozone measurements.

The uncertainty of these parameters is characterized by the standard error:

$S E=\frac{S D}{\sqrt{N}}$

where $N$ is the number of data and $S D$ is the standard deviation.

\section{Results and discussion}

The first step in the comparison was to fit the Brewer and GOME data using a linear regression analysis. Figure 2 shows the scatter plots between GOME versus Brewer ozone data for each station and for all data together (referred to as the Iberian Peninsula). The solid line is the regression line and the dashed line is the zero bias line 
MADRID

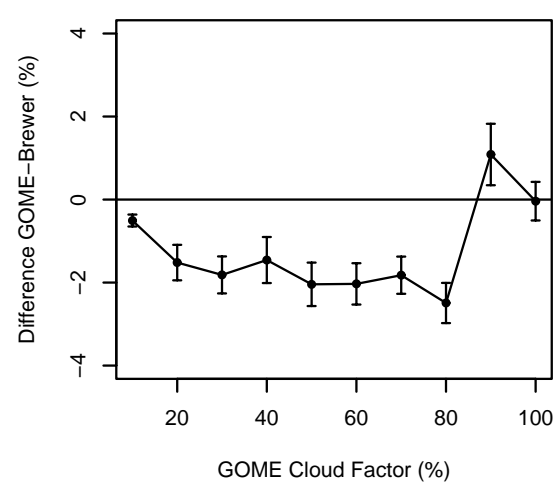

ZARAGOZA

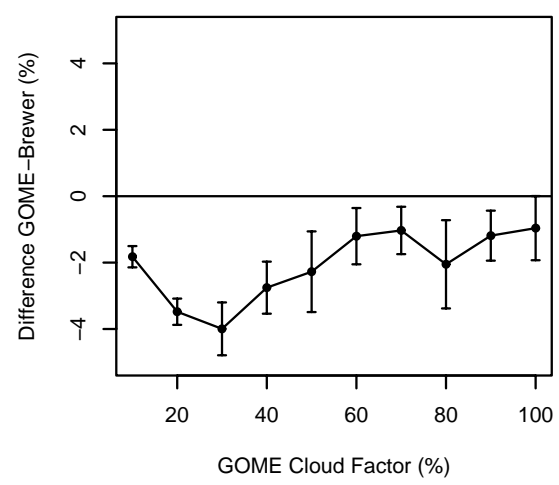

ARENOSILLO

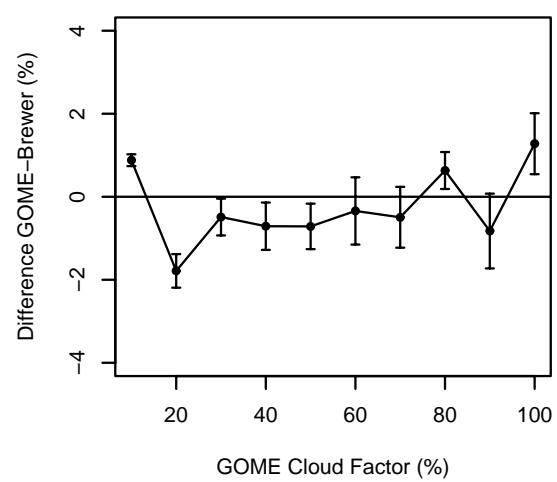

CORUÑA

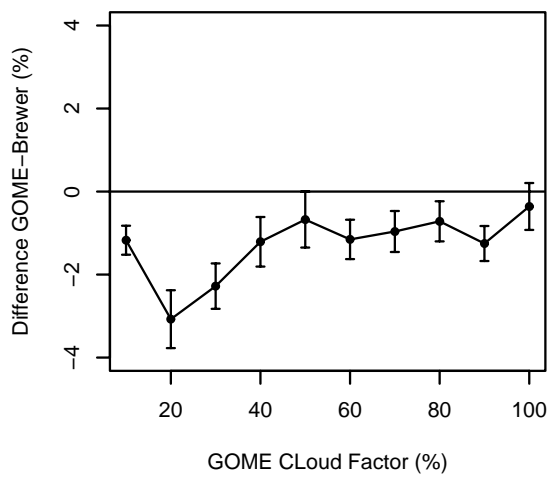

MURCIA

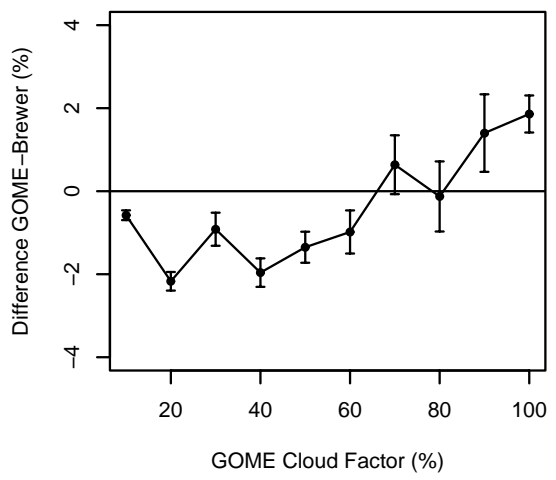

IBERIAN PENINSULA

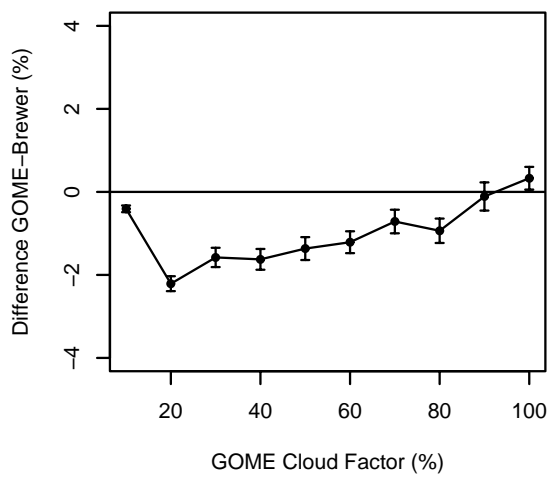

Fig. 4. Dependence of GOME-Brewer relative differences with the GOME Cloud Factor.

(unit slope). The slopes and statistical parameters obtained in these correlations are shown in Table 2. The correlation between GOME and Brewer data is high for all stations $\left(R^{2} \sim 0.92\right)$. Moreover, the noise is significantly low in all cases: RMSE $=3.29 \%$ for Coruña (maximum) and RMSE $=2.36 \%$ for Zaragoza (minimum). In addition, the MABE is lower than 3.3\% in all locations. The standard error in the MABE is lower than $0.10 \%$, indicating the statistical significance of the reported values. The analysis of all data together confirms these excellent results. The negative sign of the MBE parameters indicates that GOME underestimates the Brewer measurements in all locations except Arenosillo station, where the positive value of the MBE parameter denotes a slight overestimation.

To further analyse the differences between the GOME and Brewer observations, we examined the temporal evolution of the differences and the dependence on cloudiness, solar zenith angle (SZA), effective temperature and total ozone amount. 

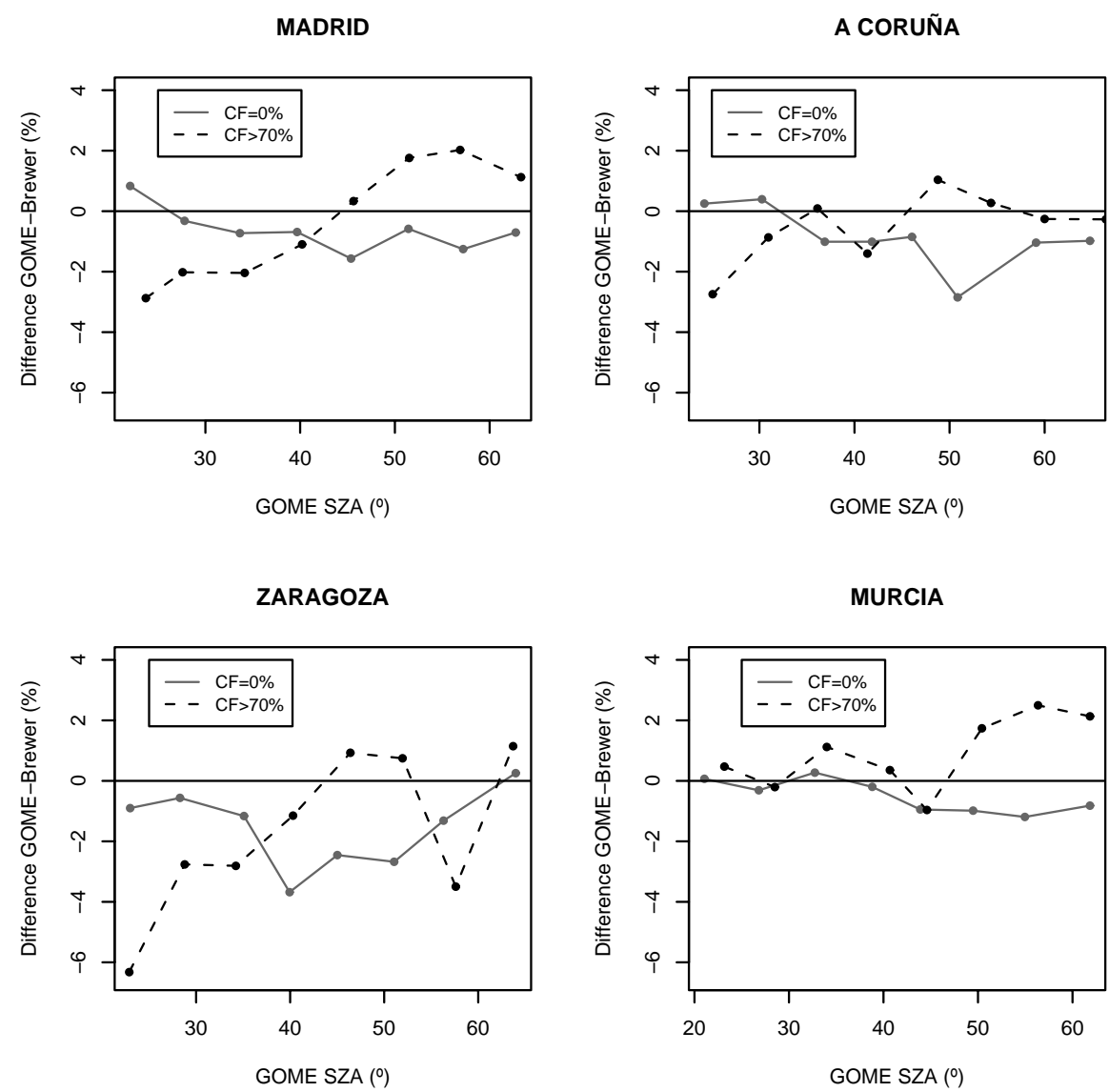

ARENOSILLO
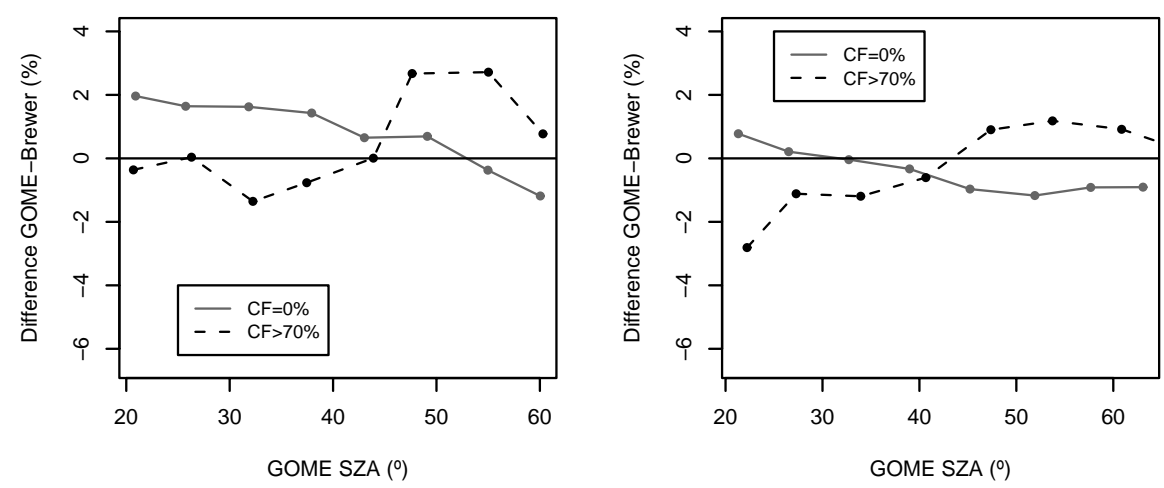

Fig. 5. Variation of GOME-Brewer relative differences with the solar zenith angle for cloud-free conditions and heavy cloud conditions.

The temporal evolution of the differences for each station is presented in Fig. 3. The data gaps in the station plots of Murcia and Madrid are due to a lack of reliable Brewer spectrophotometer data during those periods. From Fig. 3, we can see that the differences between the GOME and Brewer observations are mostly within 10\%. The GOME-Brewer differences are generally small in the winter-spring period, while in summer-autumn GOME underestimates groundbased ozone values by $2-4 \%$. On average, this seasonality has an amplitude of $1-2 \%$, which is consistent with previous studies (e.g. Balis et al., 2007). Furthermore, the temporal evolution of the differences does not show any clear trend.

In the GOME total ozone retrieval, the cloud properties (cloud fraction, cloud-top height, and cloud-top albedo) play an important role in the calculation of the AMF and in the estimation of the ghost column hidden by the cloud (van Roozendael et al., 2006). To further analyse the influence of clouds on the GOME total ozone retrieval, we plotted the relative difference between GOME and Brewer total ozone as a function of the GOME cloud fraction (Fig. 4). 
MADRID

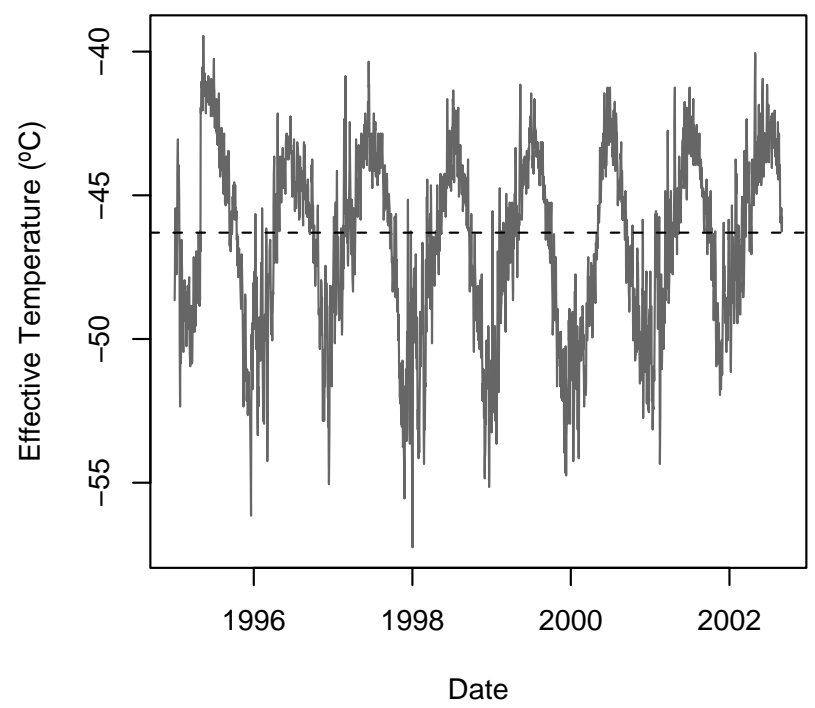

Fig. 6. Temporal evolution of effective temperature at the Madrid station.

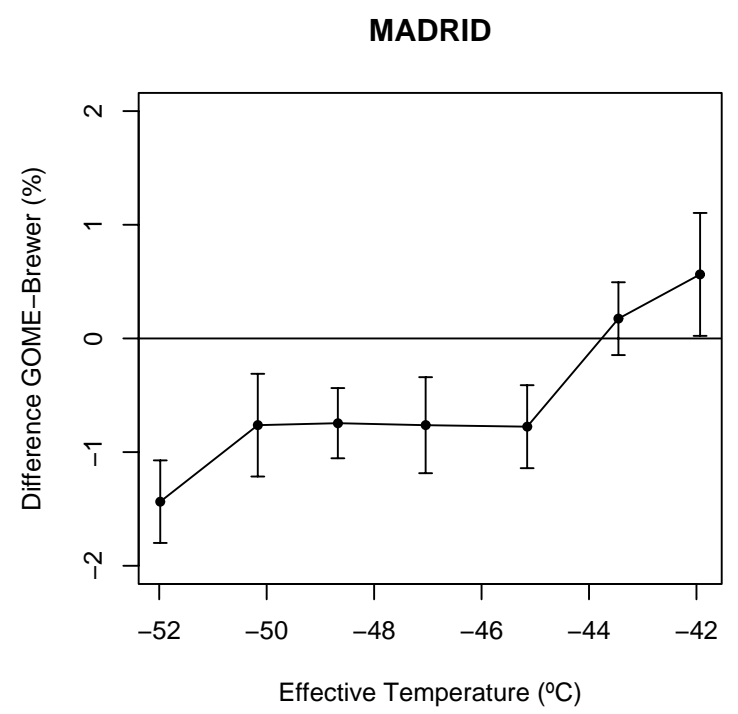

Fig. 7. Variation of GOME-Brewer relative differences with the effective temperature at the Madrid station.

As expected, the scatter of the comparison is larger with increasing cloud fraction. In cases of cloud-free conditions, $(\mathrm{CF}<5 \%)$, the differences are close to zero. When the satellite detects little cloudiness, $(5 \%<\mathrm{CF}<20 \%)$, the difference generally increases to $\sim 2 \%$. The differences also present a smooth, positive dependence with the CF values; for higher $\mathrm{CF}$ values the differences are close to zero. This dependency could be related to the GDP 4.0 estimation of the ghost tropospheric ozone (GVC parameter) which is located below the clouds. Indeed it has been recently identified that the GVC and therefore the GOME total ozone tend to be overestimated

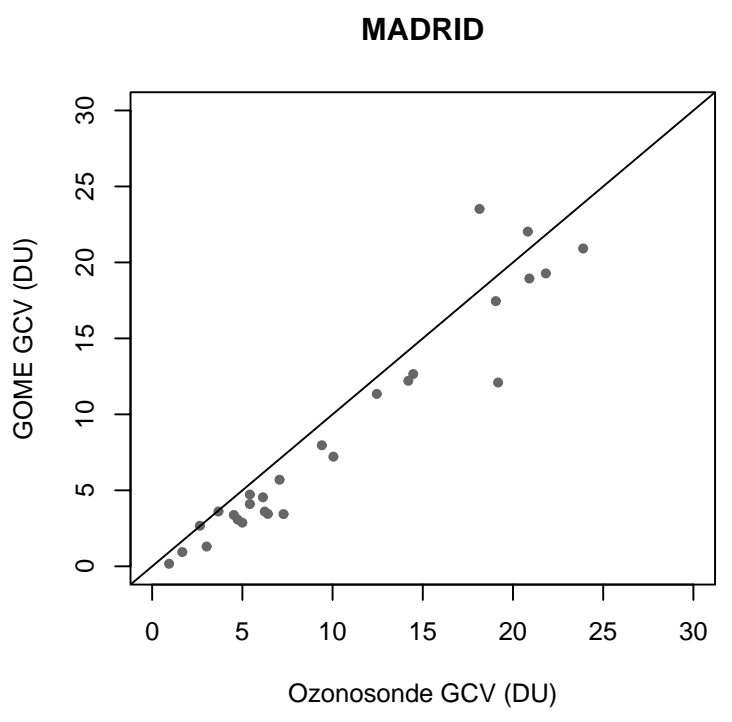

Fig. 8. GOME Ghost vertical column (GVC) versus Ozonosonde GVC at the Madrid station. Line of unit slope (solid line).

because the GVC dependency on the cloud-top albedo has not been considered in GDP 4.0. In addition, the cloudiness influence in the GOME-Brewer differences might also be related to the GDP estimation of AMFs for cloudy conditions.

Further analysis of relative differences between GOME and ground-based total ozone shows no significant dependence on the GOME SZA in the Iberian Peninsula. This is in agreement with other GOME validation studies (ESA, 2004; Balis et al., 2007). The SZA dependence has also been analyzed for two antagonistic conditions: cloud-free $(\mathrm{CF}<5 \%)$ and heavy cloud condition $(\mathrm{CF}>70 \%)$. The percentage of cases selected is about $40 \%$ and $20 \%$, respectively which shows the prevalence of cloudless situations in Spain. Figure 5 shows the relative differences between GOME and Brewer data as a function of the SZA considering the two data set. For cloud-free cases, GOME observations overestimate ground-based Brewer data for low SZA by -1 and $+2 \%$ while for high SZA the satellite underestimates ground-based ozone values by down to $-1 \%$, resulting in a maximum amplitude of about $3 \%$. In contrast, for heavy cloud conditions the evolution of differences is completely opposite. The minimum differences (between $-6 \%$ and $+1 \%$ ) are obtained for low SZA zenith angles and the maximum (between $1 \%$ and $3 \%$ ) for high SZA values. Therefore, the null dependence of the relative differences when all conditions are used could be attributed to the compensation of cases with cloud-free and heavy cloud conditions. When cloud-free conditions are selected, the relationship between the differences and SZA may be due, in part, to the seasonal dependence (lower SZA in summer, higher SZA in winter).

Next, the influence of the stratospheric temperature variation on GOME-Brewer differences is analyzed for cloud-free conditions. To this end, an effective temperature has been calculated using the European Centre for Medium Range 
Weather Forecasts (ECMWF) Reanalysis ERA-40 (19572002) data (Uppala et al., 2005):

$T_{\text {eff }}=\frac{\int \rho(z) \cdot T(z) d z}{\int \rho(z) d z}$,

where $T(z)$ and $\rho(z)$ are the temperature and the ozone concentration vertical profiles, and $\int \rho(z) d z$ is the corresponding vertical ozone column. Both the ozone profiles and temperature profiles are from the ECMWF model. In this model, SBUV (Solar Backscatter Ultraviolet) and TOMS (Total Ozone Mapping Spectrometer) ozone data have been assimilated.

Figure 6 shows the evolution of the daily effective temperature for Madrid between 1995 and 2002. The dashed line indicates the Brewer standard temperature of $-46.3^{\circ} \mathrm{C}$. The actual effective temperature in Madrid varies in mean terms about $5^{\circ} \mathrm{C}$ around that standard temperature. It is known that the variability of effective temperature can cause a low dependence $\left(+0.07 \% /{ }^{\circ} \mathrm{C}\right)$ in Brewer ozone measurements (Kerr, 1988). Thus, the Brewer error due to effective temperature variability is at maximum about $0.35 \%$. Figure 7 shows that the GOME-Brewer differences for cloudfree cases have a significant dependence with effective temperature (amplitude of $2 \%$ ). The positive biases are obtained for the warmest temperatures which are reached during summer months (see Fig. 6). This fact is related to the positive GOME-Brewer differences for low SZA, as shown in Fig. 5. This behaviour is also observed in Murcia and Arenosillo. Therefore, from the $2 \%$ amplitude of GOME-Brewer differences attributed to the effective temperature fluctuations, only $0.35 \%$ at maximum is due to the Brewer instrument.

Uncertainties in the GOME cloud parameters and in the GVC could be a cause for the evolution of the differences observed in Fig. 5 for CF higher than $70 \%$.

To study the accuracy of the GVC used in the GOME retrieval algorithm, 28 simultaneous satellite and ozonesondes observations, corresponding to cloudiness cases at Madrid, have been selected. A set of "ozonesonde" GVC have been obtained from the ozonesonde measurements and the cloudtop height estimated by GOME. The ozonesonde GVC is compared with the GOME GVC (based on the TOMSV8 profiles climatology) in Fig. 8. From this figure, it can be seen that the GOME observations of the GVC parameter underestimate the ozonesonde measurements in most cases, by about $23 \%$, on average (in absolute value this percentage represents less than $2 \mathrm{DU})$. This underestimation is due to the deviations of the TOMSV8 ozone profile climatology from the real atmospheric conditions. However, the GVC represents about $3 \%$ of total ozone column, on average (7\% maximum) for the 28 ozonosondes observations that were analyzed. Therefore the notable uncertainty in the GOME GVC parameter should not have a great influence in the total ozone GOME estimations.
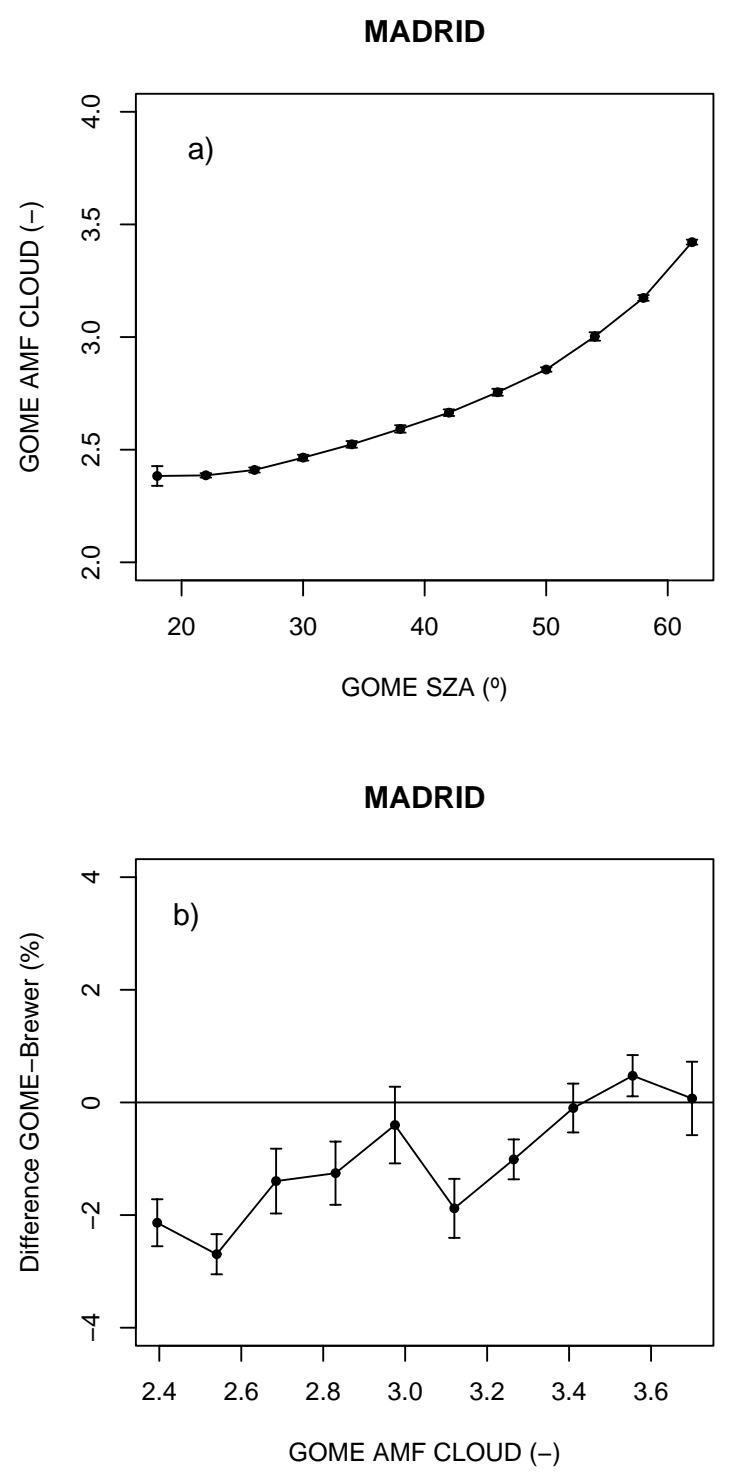

Fig. 9. (a) Dependence of AMF parameter with solar zenith angle for the Madrid station. (b) Variation of GOME-Brewer relative differences with the AMF parameter at the Madrid station.

The influence of cloudy AMF in GOME-Brewer differences for cases with $\mathrm{CF}>70 \%$ in Madrid is analyzed. Figure 9a shows that the variation of cloudy AMF depends strongly on the SZA variability. The lowest and highest values of the AMF cloud parameter occurs for low SZA values (summer periods) and high SZA values (winter periods), respectively. It is interesting to note that the evolution of the GOME-Brewer differences caused by the cloudy AMF (Fig. 9b) follows the SZA dependence of cloudy AMF values (Fig. 9a). Thus, GOME underestimates Brewer data for low AMF values (low SZA). In contrast, GOME-Brewer differences are close to zero for high AMF values (high SZA). Moreover, it is possible to relate the two graphics in Fig. 9 

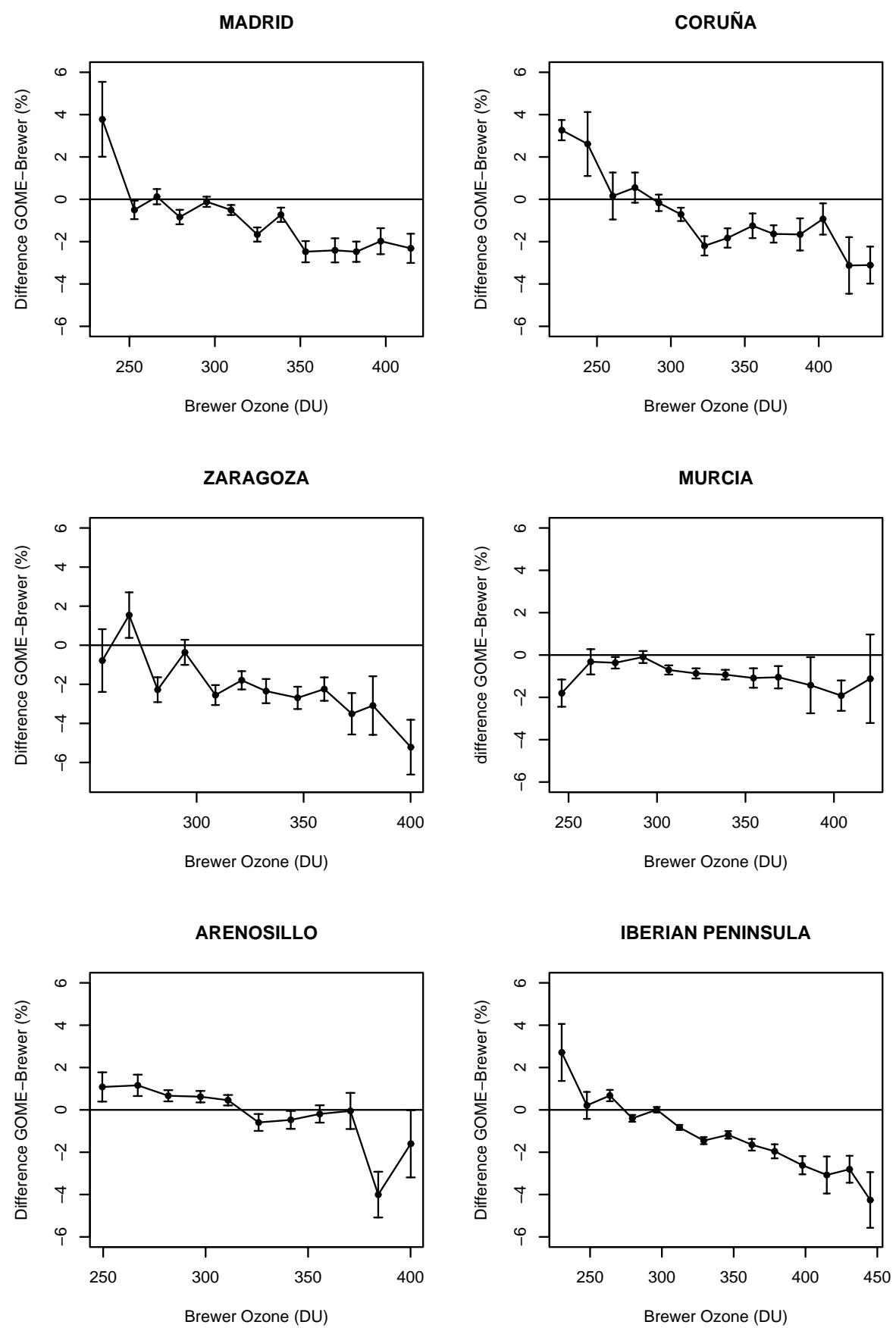

Fig. 10. Variation of GOME-Brewer relative differences with Brewer ozone measurements.

with the trend of differences observed in Fig. 5 (see Madrid) for cases with $\mathrm{CF}>70 \%$. Thus, the evolution of the GOMEBrewer differences for the heavy cloud conditions shown in Fig. 5 for high SZA seems to indicate that it could be due to errors introduced by the cloudy AMF factor.

Finally, we study the influence of the total ozone amount on the GOME-Brewer difference. Figure 10 shows the relative differences as a function of the Brewer ozone column.
All plots show that low ozone amounts (240-250 DU) are overestimated by the GOME satellite (1-4\%). In contrast, high ozone values (380-420 DU) are underestimated (2$4 \%$ ). Therefore, GOME satellite observations do not completely cover the ozone variability recorded by the Brewer. 


\section{Conclusions}

Some important conclusions may be drawn from the GOMEBrewer comparison over five locations in the Iberian Peninsula. In general, the average agreement of GDP 4.0 with Brewer ozone measurements falls within the precision level of ground-based sensors and the correlation between the two instruments is excellent. We have checked the influence of several parameters (cloud fraction, AMF, SZA, effective temperature and ozone amount) on the GOME-Brewer differences.

The best agreement between satellite observations and ground-based measurements is obtained for low SZA values and cloud-free cases. In addition, the GOME-Brewer differences present an opposite pattern with SZA values for cloud-free and cloudy conditions. For cloud free cases, the dependence may be caused by both seasonal fluctuations of the GOME-Brewer differences and the effective temperature variability. It is interesting to note that this last factor produces a notable dependence over the GOME-Brewer differences (about 2\%). It is known that ozone Brewer values present a very low dependence with the effective temperature. Therefore, the results of this paper may indicate that in spite the inclusion of the characterization of the ozone absorption temperature, the GDP 4.0 algorithm presents an important uncertainty due to the variation of the ozone absorption cross section with the effective temperature.

The cloudiness introduces a significant dependence of the GOME-Brewer differences on the SZA values. This fact could be related to errors in the satellite estimation of the AMF cloud parameter. Thus, this work has verified that there is a notable relationship between the GOME-Brewer differences and the AMF cloud parameter. In contrast, deviations in the GVC ozone parameters should not have a notable influence on the variability of the GOME-Brewer differences. Finally, one also concludes that the GOME ozone total columns slightly underestimate the highest values recorded by the Brewer spectrophotometers and overestimate the lowest measurements of this ground-based instrument.

Acknowledgements. The Brewer ozone data used in this study have been provided by the Instituto Nacional de Meteorología (INM) (Madrid, Murcia, Zaragoza and A Coruña) and the Instituto Nacional de Técnica Aeroespacial (INTA) (El Arenosillo). Moreover, the authors would like to thank to German Aerospace Center (DLR) for providing the GOME data. This work has been partially supported by INM with a postgraduate grant (project \#16-2005/2006) and the visiting scientist program of EUMETSAT satellite application facility for ozone and atmospheric chemistry monitoring (O3M-SAF)

Topical Editor F. D'Andrea thanks two anonymous referees for their help in evaluating this paper.

\section{References}

Balis, D., Lambert, J. C., Van Roozendael, M., Spurr, R., Loyola, D., Livschitz, Y., Valks, P., Amiridis, V., Gerard, P., Granville, J., and Zehner, C.: Ten years of GOME/ERS2 total ozone data: the new GOME Data Processor (GDP) Version 4: II. Groundbased validation and comparisons with TOMS V7/V8, J. Geophys. Res., 112, D07307, doi:10.1029/2005JD006376, 2007.

Bramstedt, K., Gleason, J., Loyola, D., Thomas, W., Bracher, A., Weber, M., and Burrows, J. P.: Comparison of total ozone from the satellite instruments GOME and TOMS with measurements from the Dobson network 1996-2000, Atmos. Chem. Phys., 3, 1409-1419, 2003, http://www.atmos-chem-phys.net/3/1409/2003/.

Burrows, J. P., Weber, M., Buchwitz, M., Razonov, V., Ladstatter, A., Richter, A. De Beerk, R., Hoogen, R. , Bramsdted, D., Eichmann, K. U., Eisenger, M., and Perner, D.: The Global Ozone Monitoring Experiment (GOME): mission concept and first scientific results, J. Atmos. Sci., 56, 151-175, 1999.

European Spatial Agency: GOME Global Ozone Monitoring Experiment Users Manual, ESA, SP-1182, 1995.

European Spatial Agency: GOME geophysical validation campaign, Final Results Workshop Proc., Noorwijk, Netherlands, 268 pp., 1996.

European Spatial Agency: Delta validation report for ERS-2 GOME Data Processor upgrade to version 4.0, Technical Note ERSE-CLVL-EOPG-TN-04-0001, 2004.

Hansen, G., Dahlback, A., Tønnessen, F., and Svenøe, T.: Validation of GOME total ozone by means of the Norwegian ozone monitoring network, Ann. Geophys., 17, 430-436, 1999, http://www.ann-geophys.net/17/430/1999/.

Kerr, J. B., McElroy, C., and Evans, V.: The automated Brewer spectrophotometer, In Proc. Quadrenial Ozone Symposium, Haldidiki, Greece, 396-401, 1984.

Kerr, J. B., Asbridge, A., and Evans, W. F. J.: Intercomparison of total ozone measured by Brewer and Dobson spectrophotometer at Toronto, J. Geopshys. Res., 93, 11 129-11 140, 1988.

Kerr, J. B.: New methodology for deriving total ozone and other atmospheric variables from Brewer spectrophotometer direct sun spectra, J. Geopshys. Res., 107(D23), 4731, doi:10.1029/2001JD001227, 2002.

Labajo, A., Cuevas, E., and de la Morena, B.: The first Iberian UV-visible instrument intercomparison. Final report. Edited by Instituto Nacional de Meterorologia (INM, Spain), 2004.

Lambert, J. C., Peeters, P., Richter, A., et al.: ERS-2 GOME data products delta characterization report, Isuue 0.1, edited by: Lambert, J. C. and Skarlas, P., November 1999.

Lambert, J. C., Hansen, G., Soebijanta, V., Thomas, W., Van Roozendal, M., Balis, D., Fayt, C., Gerard, P., Gleason, J., Granville, J., Labow, G., Loyola, D., van Geffen, J., van Oss, R., Zehner, C., and Zerefos, C.: ERS-2 GOME GDP3.0 Implementation and Delta Validation Report for GOME Level-1 to Level 2 Data Processor Upgrade to Version 3.0, ESA Technical Note ERSE-DTEX-EOAD-TN-02-0006, 2002.

Loyola, D., Balzer, W., Aberle, B., Bittner, M., Kretschel, K., Mikusch, E., Muehle, H., Ruppert, T., Schmid, C., Slijkhuis, S., Spurr, R., Thomas, W., Wieland, T. and Wolfmueller, M..: Ground segment for ERS-2/GOME sensor at the German D-PAF, 3rd ERS Scientific Symposium, Florence, Italy, 591-596, 1997.

Loyola, D., Thomas W., Livschitz Y., Ruppert T., Albert P., and 
Hollmann R.: Cloud Properties Derived from GOME/ERS-2 Backscatter Data for Trace Gas Retrieval, IEEE Transactions on Geoscience and Remote Sensing, 45(9), 2747-2758, 2007.

van Roozendael, M., Loyola, D., Spurr, R., Balis, D., Lambert, J.C., Livschitz, Y., Valks, P., Ruppert, T., Kenter, P., Fayt, C., and Zehner, C.: Ten years of GOME/ERS2 total ozone data: the new GOME Data Processor (GDP) Version 4:I. Algoritm Description, J. Geophys. Res., 111, D14311, doi:10.1029/2005JD006375, 2006.
Uppala, S. M., Kallberg, P. W., Simmons, A. J., et al.: The ERA-40 Reanalysis, Q. J. R. Meteorol. Soc., 131, 2961-3012, 2005.

World Meteorological Organization: Guide to meteorological instruments and methods of observation, 6th ed. WMO Publication \#8, Geneva, 1996.

World Meteorological Organization: WMO/CEOS report on a strategy for integrating satellite and ground-based observations of ozone, GAW Technical Report n ${ }^{\circ} 140,1999$. 